\title{
Extra-cerebral Metastasis - An Independent Predictor of Survival in Older Patients With Brain Metastases Receiving a Local Therapy Plus Whole-Brain Radiotherapy (WBRT)
}

\author{
DIRK RADES ${ }^{1}$, TRANG NGUYEN ${ }^{1}$ and STEVEN E. SCHILD ${ }^{2}$ \\ ${ }^{1}$ Department of Radiation Oncology, University of Lübeck, Lübeck, Germany; \\ ${ }^{2}$ Department of Radiation Oncology, Mayo Clinic, Scottsdale, AZ, U.S.A.
}

\begin{abstract}
Background/Aim: Although omitting whole-brain radiotherapy (WBRT) during the treatment of few brain metastases more popular, many patients receive local therapies plus WBRT. WBRT may be less reasonable for patients with poor overall survival $(O S)$, particularly if they are older. This study aimed to identify predictors of $O S$ in these patients. Patients and Methods: One-hundred-and-two older patients receiving a local therapy (surgery, radiosurgery, simultaneous integrated boost) and WBRT for 1-3 brain metastases were evaluated. Type of local therapy, WBRT-regimen, age, gender, performance status, primary tumour type, number of brain metastases, extra-cerebral metastasis, and interval from tumour diagnosis to treatment of brain metastases were analysed for OS. Results: Absence of extra-cerebral metastasis was significantly associated with increased $O S$ on univariate analysis $(p=0.001)$ and Cox regression analysis (risk ratio $=2.13, p=0.002$ ). Conclusion: Extra-cerebral metastasis is an independent predictor of $O S$ and can be helpful when assigning a treatment to older patients with few brain metastases.
\end{abstract}

Secondary malignant lesions in the brain are about ten times more common than primary brain tumours (1). Treatment varies depending on several factors including the number of brain metastases (2). The majority of patients with multiple cerebral lesions, mostly defined as more than three lesions, receive whole-brain radiotherapy (WBRT) alone. In patients with oligo-metastases, i.e. patients with 1 to 3 lesions, WBRT alone is generally limited to patients with a poor

This article is freely accessible online.

Correspondence to: Professor Dirk Rades, MD, Department of Radiation Oncology, University of Lubeck, Lubeck, Ratzeburger Allee 160, 23562 Lubeck, Germany. Tel: +49 45150045401, Fax: +49 45150045404, e-mail: rades.dirk@gmx.net

Key Words: Older patients, brain metastases, local therapies, wholebrain radiotherapy, overall survival, extra-cerebral metastasis. performance status or very large unresectable metastases (2). Many patients with oligo-metastatic brain disease are treated with a local therapy including surgical resection and radiosurgery $(3,4)$. Local therapies are increasingly administered alone; however, in a considerable number of patients they are combined with WBRT (2-4). In several studies and a meta-analysis of patients with 1 to 3 brain metastases, a radiosurgery-boost in addition to WBRT led to significant improvement of intracerebral control (5-8). Moreover, several previous studies and two meta-analyses have found that the addition of WBRT to surgery or radiosurgery improved intracerebral control and local control of the treated metastases and delayed the development of new brain metastases (8-15). Since two randomized trials have demonstrated that the addition of WBRT was associated with a significantly greater extend of cognitive decline, physicians have become more reserved regarding WBRT in combination with surgery and radiosurgery $(16,17)$. However, an intracerebral recurrence was shown to be associated with cognitive dysfunction as well, and modern approaches to reduce cognitive decline such as hippocampal sparing and memantine were not used in these two trials (1820). Therefore, the role of WBRT, when added to a local therapy, requires further clarification. One aspect that should be considered, when thinking of combining a local therapy and WBRT, is the probability of developing new brain metastases outside the treated areas. If this probability, which can be estimated with a scoring system, is high, the patients should be considered for WBRT (21). Another aspect is a patient's remaining lifespan. Since the risk of cognitive decline increases with time, this aspect is particularly important for longer-term survivors. Therefore, prognostic factors of survival in patients who may be candidates for a local therapy plus WBRT would be helpful. This accounts particularly for older patients, who often are unable to withstand intensive combined treatments. For many older patients with a limited lifespan, a short course of WBRT instead of a more aggressive local therapy may be preferable (22). To facilitate the decision-making process when 
Table I. Patient characteristics and potential prognostic factors.

\begin{tabular}{|c|c|}
\hline Factor & $\begin{array}{l}\text { Number of } \\
\text { patients }(\%)\end{array}$ \\
\hline \multicolumn{2}{|l|}{ Type of treatment } \\
\hline WBRT + RS & $21(20.6)$ \\
\hline Surgery + WBRT & $65(63.7)$ \\
\hline $\mathrm{WBRT}+\mathrm{SIB}$ & $16(15.7)$ \\
\hline \multicolumn{2}{|l|}{ Dose-fractionation of WBRT } \\
\hline 20 Gy in 5 fractions & $8(7.8)$ \\
\hline $30 \mathrm{~Gy}$ in 10 fractions & $55(53.9)$ \\
\hline $35-40 \mathrm{~Gy}$ in $14-20$ fractions & $39(38.2)$ \\
\hline \multicolumn{2}{|l|}{ Age at start of treatment } \\
\hline$\leq 69$ Years & $54(52.9)$ \\
\hline$\geq 70$ Years & $48(47.1)$ \\
\hline \multicolumn{2}{|l|}{ Gender } \\
\hline Female & $44(43.1)$ \\
\hline Male & $58(56.9)$ \\
\hline \multicolumn{2}{|l|}{ Performance status } \\
\hline $\mathrm{KPS} \leq 70$ & $37(36.3)$ \\
\hline $\mathrm{KPS} \geq 80$ & $65(63.7)$ \\
\hline \multicolumn{2}{|l|}{ Primary tumor type } \\
\hline Breast cancer & $13(12.7)$ \\
\hline NSCLC & $42(41.2)$ \\
\hline SCLC & $14(13.7)$ \\
\hline Other types & $33(32.4)$ \\
\hline \multicolumn{2}{|l|}{ Number of brain metastases } \\
\hline 1 & $72(70.6)$ \\
\hline 2 or 3 & $30(29.4)$ \\
\hline \multicolumn{2}{|l|}{ Extra-cerebral metastasis } \\
\hline Absence & $58(56.9)$ \\
\hline Presence & $44(43.1)$ \\
\hline \multicolumn{2}{|l|}{$\begin{array}{l}\text { Interval from tumor diagnosis to } \\
\text { the first day of treatment }\end{array}$} \\
\hline$\leq 4$ Months & $51(50.0)$ \\
\hline$\geq 5$ Months & $51(50.0)$ \\
\hline
\end{tabular}

WBRT: Whole-brain radiotherapy; RS: radiosurgery; SIB: simultaneous integrated boost, KPS: Karnofsky performance score; NSCLC: nonsmall cell lung cancer; SCLC: small-cell lung cancer.

physicians have to assign a treatment to an older patient with oligo-metastatic brain disease, the present study aimed to identify independent predictors of survival in a cohort of older patients who had received a local therapy plus WBRT.

\section{Patients and Methods}

A cohort of 102 older patients, aged 65 or more years, was included in this retrospective study, which was approved by the local Ethics Committee. These patients were treated with a combination of local therapy and WBRT for 1 to 3 brain metastases between 1995 and 2019 . Local therapies included pre-WBRT surgery $(n=65)$, postWBRT single-fraction radiosurgery $(\mathrm{n}=21)$ and a simultaneous integrated boost given concurrently with WBRT using volumemodulated arc therapy $(n=16)$. WBRT-regimens included 20 Gy in 5 fractions $(n=8), 30$ Gy in 10 fractions $(n=55)$ and $35-40 G y$ in 14 -
Table II. Overall survival rates at 6 and 12 months.

\begin{tabular}{|c|c|c|c|}
\hline Factor & $\begin{array}{l}6 \text { mos. } \\
(\%)\end{array}$ & $\begin{array}{l}12 \text { mos. } \\
(\%)\end{array}$ & $p$-Value \\
\hline \multicolumn{4}{|l|}{ Type of treatment } \\
\hline WBRT + RS & 67 & 28 & \multirow[t]{3}{*}{0.440} \\
\hline Surgery + WBRT & 60 & 31 & \\
\hline WBRT + SIB & 44 & 44 & \\
\hline \multicolumn{4}{|l|}{ Dose-fractionation of WBRT } \\
\hline 20 Gy in 5 fractions & 63 & 63 & \multirow[t]{3}{*}{0.308} \\
\hline $30 \mathrm{~Gy}$ in 10 fractions & 62 & 27 & \\
\hline $35-40$ Gy in $14-20$ fractions & 54 & 33 & \\
\hline \multicolumn{4}{|l|}{ Age at start of treatment } \\
\hline$\leq 69$ Years & 56 & 31 & \multirow[t]{2}{*}{0.683} \\
\hline$\geq 70$ Years & 63 & 32 & \\
\hline \multicolumn{4}{|l|}{ Gender } \\
\hline Females & 59 & 31 & \multirow[t]{2}{*}{0.792} \\
\hline Males & 59 & 33 & \\
\hline \multicolumn{4}{|l|}{ Performance status } \\
\hline KPS $\leq 70$ & 51 & 24 & \multirow[t]{2}{*}{0.221} \\
\hline $\mathrm{KPS} \geq 80$ & 63 & 36 & \\
\hline \multicolumn{4}{|l|}{ Primary tumor type } \\
\hline Breast cancer & 54 & 19 & \multirow[t]{4}{*}{0.530} \\
\hline NSCLC & 62 & 32 & \\
\hline SCLC & 64 & 28 & \\
\hline Other types & 55 & 36 & \\
\hline \multicolumn{4}{|l|}{ Number of brain metastases } \\
\hline 1 & 63 & 34 & \multirow[t]{2}{*}{0.198} \\
\hline 2 or 3 & 50 & 25 & \\
\hline \multicolumn{4}{|l|}{ Extra-cerebral metastasis } \\
\hline Absence & 69 & 46 & \multirow[t]{2}{*}{0.001} \\
\hline Presence & 45 & 14 & \\
\hline \multicolumn{4}{|l|}{$\begin{array}{l}\text { Interval from tumor diagnosis to } \\
\text { the first day of treatment }\end{array}$} \\
\hline$\leq 4$ Months & 57 & 34 & \multirow[t]{2}{*}{0.981} \\
\hline$\geq 5$ Months & 61 & 30 & \\
\hline
\end{tabular}

WBRT: Whole-brain radiotherapy; RS: radiosurgery; SIB: simultaneous integrated boost; KPS: Karnofsky performance score; NSCLC: nonsmall cell lung cancer; mos.: months; SCLC: small-cell lung cancer; bold $p$-value is significant.

20 fractions $(n=39)$. Type of local therapy, WBRT-regimen and seven other factors were analysed for potential associations with overall survival (OS) (Table I). These factors included age at the onset of brain metastases treatment ( $\leq 69$ versus $\geq 70$ years, median age $=69$ years), gender, patient's performance status (given as Karnofsky performance score, KPS $\leq 70$ versus $\geq 80$, median KPS $=80$ ), primary tumor type (breast cancer versus non-small cell lung cancer, small-cell lung cancer, other types), number of brain metastases ( 1 versus 2 or 3), extra-cerebral metastasis (absence versus presence) and interval from tumour diagnosis to the first day of treatment of brain metastases ( $\leq 4$ versus $\geq 5$ months).

Time to death was calculated from the first day of treatment, namely the day of surgery or the first day of radiation therapy. Initially, all nine factors were analysed in univariate analyses including the Kaplan-Meier method and the log-rank test. Significant factors $(p<0.05)$ were subsequently evaluated for independence (also defined as $p<0.05$ ) in a Cox regression analysis. 


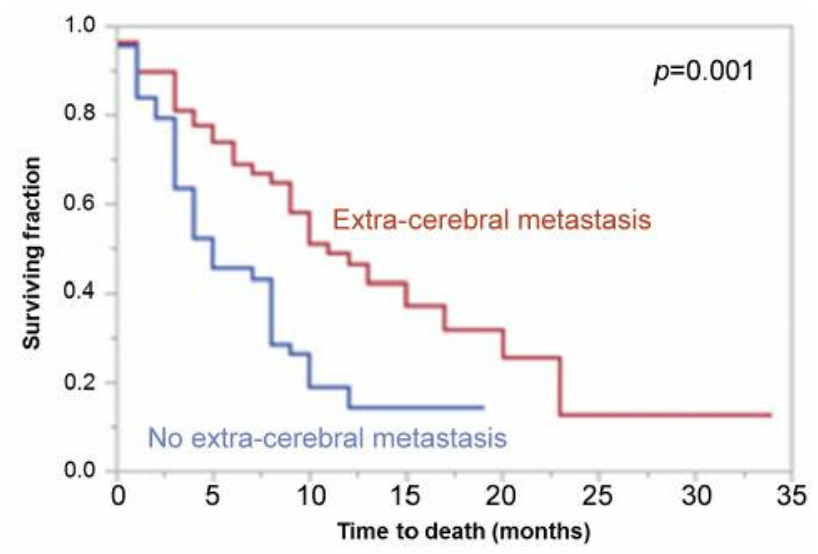

Figure 1. Kaplan-Meier curves for the overall survival (OS) of patients with and without extra-cerebral metastasis.

\section{Results}

Median follow-up times were 7 months (range=0-34 months) in all patients and 12 months (range=6-34 months) in those patients who were alive at their last contact with a medical institution. The median OS of all 102 patients was 8 months, and the OS-rates at 6 and 12-months were 59\% and 32\%, respectively. On univariate analyses (Table II), absence of extra-cerebral metastasis was the only factor that showed a significant association with increased OS (Figure 1, $p=0.001)$. In the subsequent Cox regression analysis, this association was demonstrated to be independent. The risk ratio was 2.13 , and the $95 \%$ confidence interval was 1.32 to $3.47(p=0.002)$.

\section{Discussion}

The optimal treatment protocol for patients with very few brain metastases requires further clarification. Local therapies such as surgery and radiosurgery, administered alone or in combination with WBRT, have become increasingly popular for these patients during the last 15 years (2-15). For about 10 years, when a small randomized trial $(n=58)$ suggested that the rate of post-treatment cognitive dysfunction was significantly higher after radiosurgery plus WBRT than after radiosurgery alone, physicians became more reserved regarding the addition of WBRT (16). The trial was stopped prematurely by the data safety monitoring board, because cognitive dysfunction after 4 months was observed four times more often in the radiosurgery plus WBRT arm (96\% versus $24 \%, p<0.001)$. However, intracerebral control rates at 12 months were significantly lower when WBRT was added $(27 \%$ versus $73 \%, p<0.001)(16)$. Since neuro-cognitive testing was not performed at 12 months, it remained unclear whether the higher rate of new or recurrent cerebral metastases led to impairment in cognitive functions, as previously suggested in the study of Aoyama et al. (18). In 2013, the results of the Alliance trial were published, demonstrating a significant difference regarding the rate of cognitive decline after 3 months, i.e. $92 \%$ with and $64 \%$ without WBRT $(p<0.001)$ (17). However, intracerebral progression rates after 6 and 12 months were $12 \%$ and $15 \%$, respectively, after radiosurgery plus WBRT compared to $35 \%$ and $50 \%$, respectively, after radiosurgery alone $(p<0.001)$. Thus, patients with a comparatively high risk of intracerebral progression after radiosurgery alone should be considered for additional WBRT. These patients can be identified with a scoring system reported in 2014 (21). Based on the number of brain metastases, primary tumour type and presence of extracerebral metastasis, three groups were formed with 6-month rates of freedom from distant brain metastasis of $36 \%, 65 \%$ and $80 \%$, respectively $(p<0.001)$. Since patients of the first group had a 64\%-probability of developing new brain metastases within 6 months following radiosurgery alone, they appeared good candidates for addition of WBRT (21).

Another aspect that should be considered when administering a combined treatment of surgery or radiosurgery is the patient's survival time. On one hand, cognitive decline is considered a radiation-related late toxicity, and its risk increases with time (2). However, the risk of experiencing new or recurrent brain metastases also increases with time. For several tumour entities including melanoma, new treatment concepts combine surgery or radiosurgery with new systemic drugs that have the potential to cross the blood-brain barrier $(23,24)$. However, these new drugs can be associated with considerable side effects that can be serious, particularly for older patients. Therefore, combining local therapies with WBRT appears a reasonable option for older patients with very few brain metastases who are at a high risk of experiencing new or recurrent brain metastases.

However, it remains a difficult to decide which older patient should receive the combined treatment. One critical aspect that plays a role during the decision-making process is the patient's remaining lifespan. Patients with a longer estimated survival and a high risk of new or recurrent brain metastases would likely benefit from adding WBRT to a local therapy. Those patients with a low risk of intracerebral progression following surgery or radiosurgery alone may receive the local therapy without WBRT. After surgery, one may consider to perform local radiation of the resection cave (25). Older patients with a poor survival prognosis may not be optimal candidates for surgery or radiosurgery at all and may be considered for a short course of WBRT alone, e.g. with 20 Gy in 5 fractions (22). To support radiation and medical oncologists when selecting the treatment for an older patient with 1 to 3 brain metastases, the present study aimed 
to detect prognostic factors independently associated with OS. Extra-cerebral metastasis was the only factor significantly associated with OS on both univariate and Cox regression analyses. Patients without extra-cerebral metastasis had 6and 12-month survival probabilities of $69 \%$ and $46 \%$, respectively. Therefore, these patients should be considered for a local therapy with or without WBRT, depending on the risk of developing new or recurrent brain metastases after local therapy alone (21). If WBRT is administered, new strategies for reducing the risk of cognitive decline, hippocampal-sparing techniques and memantine, should be strongly considered $(19,20)$. On the contrary, patients with extra-cerebral metastasis had less favourable prognoses with only $14 \%$ long-term survivors. Many of these patients may be appropriate candidates for WBRT alone instead of more aggressive local therapies (22). However, when considering these recommendations, one should also consider the fact that this is a retrospective study with its general limitations including the risk of hidden biases.

In summary, extra-cerebral metastasis proved to be an independent prognostic factor of survival in a cohort of older patients treated with a local therapy plus WBRT for 1 to 3 brain metastases. This factor can be helpful for radiation and medical oncologists when individualizing the treatment protocol to an older patient with few brain metastases.

\section{Conflicts of Interest}

On behalf of all Authors, the corresponding Author states that there are no conflicts of interest related to this study.

\section{Authors' Contributions}

D.R., T.N. and S.E.S, designed the study. T.N. and D.R. collected or provided data. D.R. and S.E.S. analysed the data and drafted the article, which was reviewed and approved by all three Authors.

\section{References}

1 Siegel RL, Miller KD and Jemal A: Cancer statistics, 2020. CA Cancer J Clin 70: 7-30, 2020. PMID: 31912902. DOI: 10.3322/ caac. 21590

2 Tsao MN, Rades D, Wirth A, Lo SS, Danielson BL, Gaspar LE, Sperduto PW, Vogelbaum MA, Radawski JD, Wang JZ, Gillin MT, Mohideen N, Hahn CA and Chang EL: Radiotherapeutic and surgical management for newly diagnosed brain metastasis(es): An American Society for Radiation Oncology evidence-based guideline. Pract Radiat Oncol 2: 210-225, 2012. PMID: 25925626. DOI: 10.1016/j.prro.2011.12.004

3 Rades D, Kueter JD, Veninga T, Gliemroth J and Schild SE: Whole brain radiotherapy plus stereotactic radiosurgery (WBRT+SRS) versus surgery plus whole brain radiotherapy (OP+WBRT) for 1-3 brain metastases: results of a matched pair analysis. Eur J Cancer 45: 400-404, 2009. PMID: 19062269. DOI: $10.1016 /$ j.ejca.2008.10.033
4 Rades D, Veninga T, Hornung D, Wittkugel O, Schild SE and Gliemroth J: Single brain metastasis: whole-brain irradiation plus either radiosurgery or neurosurgical resection. Cancer 118: 1138-1144, 2012. PMID: 21761403. DOI: 10.1002/cncr.26379

5 Andrews DW, Scott CB, Sperduto PW, Flanders AE, Gaspar LE, Schell MC, Werner-Wasik M, Demas W, Ryu J, Bahary JP, Souhami L, Rotman M, Mehta MP and Curran WJ Jr.: Whole brain radiation therapy with or without stereotactic radiosurgery boost for patients with one to three brain metastases: phase III results of the RTOG 9508 randomised trial. Lancet 363: 1665-1672, 2004. PMID: 15158627. DOI: 10.1016/S0140-6736(04)16250-8

6 Dziggel L, Janssen S, Bajrovic A, Veninga T, Trang NT, Khoa MT, Schild SE and Rades D: Local therapies can improve intracerebral control in patients with cerebral metastasis from gynecological cancers. Anticancer Res 36: 4777-4780, 2016. PMID: 27630327. DOI: 10.21873/anticanres.11035

7 Rades D, Janssen S, Bajrovic A, Khoa MT, Veninga T and Schild SE: A matched-pair analysis comparing whole-brain radiotherapy with and without a stereotactic boost for intracerebral control and overall survival in patients with one to three cerebral metastases. Radiat Oncol 12: 69, 2017. PMID: 28438175. DOI: 10.1186/ s13014-017-0804-1

8 Khan M, Lin J, Liao G, Li R, Wang B, Xie G, Zheng J and Yuan Y: Comparison of WBRT alone, SRS alone, and their combination in the treatment of one or more brain metastases: Review and meta-analysis. Tumour Biol 39: 1010428317702903, 2017. PMID: 28675121. DOI: $10.1177 / 1010428317702903$

9 Patchell RA, Tibbs PA, Regine WF, Dempsey RJ, Mohiuddin M, Kryscio RJ, Markesbery WR, Foon KA and Young B: Postoperative radiotherapy in the treatment of single metastases to the brain: a randomized trial. JAMA 280: 1485-1489, 1998. PMID: 9809728. DOI: 10.1001/jama.280.17.1485

10 Aoyama H, Shirato H, Tago M, Nakagawa K, Toyoda T, Hatano K, Kenjyo M, Oya N, Hirota S, Shioura H, Kunieda E, Inomata $\mathrm{T}$, Hayakawa $\mathrm{K}$, Katoh $\mathrm{N}$ and Kobashi G: Stereotactic radiosurgery plus whole-brain radiation therapy $v s$. stereotactic radiosurgery alone for treatment of brain metastases: a randomized controlled trial. JAMA 295: 2483-2491, 2006. PMID: 16757720. DOI: 10.1001/jama.295.21.2483

11 Rades D, Kueter JD, Hornung D, Veninga T, Hanssens P, Schild SE and Dunst J: Comparison of stereotactic radiosurgery (SRS) alone and whole brain radiotherapy (WBRT) plus a stereotactic boost (WBRT+SRS) for one to three brain metastases. Strahlenther Onkol 184: 655-662, 2008. PMID: 19107346. DOI: 10.1007/s00066-008-1946-8

12 Kocher M, Soffietti R, Abacioglu U, Villà S, Fauchon F, Baumert BG, Fariselli L, Tzuk-Shina T, Kortmann RD, Carrie C, Ben Hassel M, Kouri M, Valeinis E, van den Berge D, Collette S, Collette L and Mueller RP: Adjuvant whole-brain radiotherapy versus observation after radiosurgery or surgical resection of one to three cerebral metastases: results of the EORTC 22952-26001 study. J Clin Oncol 29: 134-141, 2011. PMID: 21041710. DOI: 1200/JCO.2010.30.1655

13 Rades D, Hornung D, Veninga T, Schild SE and Gliemroth J: Single brain metastasis: radiosurgery alone compared with radiosurgery plus up-front whole-brain radiotherapy. Cancer 118: 2980-2985, 2012. PMID: 22027993. DOI: 10.1002/cncr.26612

14 Rades D, Huttenlocher S, Hornung D, Blanck O and Schild SE: Radiosurgery alone versus radiosurgery plus whole-brain irradiation for very few cerebral metastases from lung cancer. 
BMC Cancer 14: 931, 2014. PMID: 25496194. DOI: 10.1186/1471-2407-14-931

15 Tsao MN, Xu W, Wong RK, Lloyd N, Laperriere N, Sahgal A, Rakovitch $\mathrm{E}$ and Chow E: Whole brain radiotherapy for the treatment of newly diagnosed multiple brain metastases. Cochrane Database Syst Rev 1: CD003869, 2018. PMID: 29365347. DOI: $10.1002 / 14651858 . C D 003869 . p u b 4$

16 Chang EL, Wefel JS, Hess KR, Allen PK, Lang FF, Kornguth DG, Arbuckle RB, Swint JM, Shiu AS, Maor MH and Meyers CA: Neurocognition in patients with brain metastases treated with radiosurgery or radiosurgery plus whole-brain irradiation: a randomised controlled trial. Lancet Oncol 10: 1037-1044, 2009. PMID: 19801201. DOI: 10.1016/S1470-2045(09)70263-3

17 Brown PD, Jaeckle K, Ballman KV, Farace E, Cerhan JH, Anderson SK, Carrero XW, Barker FG 2nd, Deming R, Burri SH, Ménard C, Chung C, Stieber VW, Pollock BE, Galanis E, Buckner JC and Asher AL: Effect of radiosurgery alone vs. radiosurgery with whole brain radiation therapy on cognitive function in patients with 1 to 3 brain metastases: A randomized clinical trial. JAMA 316: 401-409, 2016. PMID: 27458945. DOI: $10.1001 /$ jama.2016.9839

18 Aoyama H, Tago M, Kato N, Toyoda T, Kenjyo M, Hirota S, Shioura H, Inomata T, Kunieda E, Hayakawa K, Nakagawa K, Kobashi G and Shirato H: Neurocognitive function of patients with brain metastasis who received either whole brain radiotherapy plus stereotactic radiosurgery or radiosurgery alone. Int J Radiat Oncol Biol Phys 68: 1388-1395, 2007. PMID: 17674975. DOI: $10.1016 /$ j.ijrobp.2007.03.048

19 Gondi V, Pugh SL, Tome WA, Caine C, Corn B, Kanner A, Rowley H, Kundapur V, DeNittis A, Greenspoon JN, Konski AA, Bauman GS, Shah S, Shi W, Wendland M, Kachnic L and Mehta MP: Preservation of memory with conformal avoidance of the hippocampal neural stem-cell compartment during wholebrain radiotherapy for brain metastases (RTOG 0933): a phase II multi-institutional trial. J Clin Oncol 32: 3810-3816, 2014 PMID: 25349290. DOI: 10.1200/JCO.2014.57.2909

20 Brown PD, Pugh S, Laack NN, Wefel JS, Khuntia D, Meyers C, Choucair A, Fox S, Suh JH, Roberge D, Kavadi V, Bentzen SM, Mehta MP and Watkins-Bruner D; Radiation Therapy Oncology Group (RTOG): Memantine for the prevention of cognitive dysfunction in patients receiving whole-brain radiotherapy: a randomized, double-blind, placebo-controlled trial. Neuro Oncol 15: 1429-1437, 2013. PMID: 23956241. DOI: 10.1093/neuonc/not114
21 Huttenlocher S, Dziggel L, Hornung D, Blanck O, Schild SE and Rades D: A new prognostic instrument to predict the probability of developing new cerebral metastases after radiosurgery alone. Radiat Oncol 9: 215, 2014. PMID: 25240823. DOI: 10.1186/1748717X-9-215

22 Evers JN, Schild SE, Segedin B, Nagy V, Khoa MT, Trang NT and Rades D: A new score predicting survival prognosis after whole-brain radiotherapy alone for brain metastases in elderly patients. Anticancer Res 34: 2455-2458, 2014. PMID: 24778060.

23 Stera S, Balermpas P, Blanck O, Wolff R, Wurster S, Baumann R, Szücs M, Loutfi-Krauss B, Wilhelm ML, Seifert V, Rades D, Rödel C, Dunst J, Hildebrandt G, Arnold A, Meissner M and Kähler KC: Stereotactic radiosurgery combined with immune checkpoint inhibitors or kinase inhibitors for patients with multiple brain metastases of malignant melanoma. Melanoma Res 29: 187-195, 2019. PMID: 30802230. DOI: 10.1097/CMR.0000000000000542

24 Petrelli F, De Stefani A, Trevisan F, Parati C, Inno A, Merelli B, Ghidini M, Bruschieri L, Vitali E, Cabiddu M, Borgonovo K, Ghilardi M, Barni S and Ghidini A: Combination of radiotherapy and immunotherapy for brain metastases: A systematic review and meta-analysis. Crit Rev Oncol Hematol 144: 102830, 2019. PMID: 31733443. DOI: 10.1016/j.critrevonc.2019.102830

25 Mahajan A, Ahmed S, McAleer MF, Weinberg JS, Li J, Brown P, Settle S, Prabhu SS, Lang FF, Levine N, McGovern S, Sulman E, McCutcheon IE, Azeem S, Cahill D, Tatsui C, Heimberger AB, Ferguson S, Ghia A, Demonte F, Raza S, Guha-Thakurta N, Yang J, Sawaya R, Hess KR and Rao G: Post-operative stereotactic radiosurgery versus observation for completely resected brain metastases: a single-centre, randomised, controlled, phase 3 trial. Lancet Oncol 18: 1040-1048, 2017. PMID: 28687375. DOI: 10.1016/S1470-2045(17)30414-X
Received March 11, 2020

Revised March 19, 2020

Accepted March 20, 2020 